\title{
A Research on the Protective Measures of the Electrical Hazards in Electrical Designs
}

\author{
Xingzhi $\mathrm{Hu}^{1, \text { a }}$, Jianguo Luo ${ }^{1, \mathrm{~b}}$ \\ ${ }^{1}$ North China Institute of Science and Technology, Yanjiao-Beijing East, China,101601 \\ aemail: huxingzhi@ncist.edu.cn, bemail: luojg_1598@126.com
}

Keywords: Electrical Hazards; Induction Hazards; Electrical design; Protective Measures

\begin{abstract}
Since electric fires and induction hazards have a great influence on the safety of human life, in the process of electrical design we should take the causes of electrical hazards into consideration and give the corresponding treatment. This article involves the classifications and characteristics of electrical hazards and analyzes the key causes of them putting forward measures to prevent electrical hazards in electrical design.
\end{abstract}

\section{Introduction}

Electrical fires and induction hazards are the main electrical hazards threatening the safety of human life. That happens more frequently and causing more and more harm to humans, along with the increase of social electricity consumption. Electrical design is the initial stage of preventing electrical hazards, and the design quality can determine whether the electrical fires or the electrical hazards will occur or not. Meanwhile, in order to reduce the induction hazards, the electrical design should be standardized.

\section{Classifications and Characteristics of Electrical Hazards}

\section{Main Classifications of the Electrical Hazards}

\subsection{Induction Hazards}

The induction hazards are a kind of electric shock phenomenon after human body getting an electric shock. It often happens in this situation a part of human body contacts the electric source and forms an electric circuit. When people comes into contact with the electric source accidently, there will be varying degrees of current through the body, if this current within safe range, it is no harm to human body, otherwise in excess of the safe range it will produce recovery injury. For instance, if the current is located at the AC60Hz15 25mA, the human body will appear muscle stiffness and breathing difficulties, otherwise once the current beyond a certain range, it will cause permanent damage to the human body even death [1]. Such as the current located at the range of AC60Hz70 90mA, it will lead to heart failure or death, while higher than AC60Hz100mA, it will directly cause death [2]. In addition to the direct harm to the human body, the induction hazards also trigger the body muscle contraction. If muscle contraction happens in aerial work will cause falling, tumble and other indirect damage. The maximum contact voltage (SAFE) are as follows (Table 1):

Table 1 IEC-TC64 regulation safety voltage

\begin{tabular}{lll}
\hline \multirow{2}{*}{ Current type } & Safe voltage/V & \\
\cline { 2 - 3 } & Normal & Humid \\
\hline AC & 50 & 25 \\
DC & 120 & 60 \\
\hline
\end{tabular}

Table 1 specifies that the maximum contact voltage (SAFE) body can tolerant when the current is at $30 \mathrm{~mA}$.

\subsection{Electrical Fires}

Generally electrical fires normally refer to fire accident which caused by thermal energy encountering plenty of fuel and oxygen during the process of heat release .The thermal energy released by malfunction of electrical lines, electrical equipment or power supply equipment. 
According to their origin, electrical fires can be divided into poor wiring fire, short circuit fire, faulty contact fire and overloaded circuit fire. Electrical fires are the main form of electrical hazards and also are the important reason of fire accident. Electrical fires incidents accounted for about one-third of the national fire incidents, the campus electrical fires accounted for $40 \%$ of campus fire incidents. In recent years with the increase of production and living electricity consumption, electrical fires become more frequent and the risk is also increasing.

2.Characteristics of the Electrical Hazards

Electrical hazards are the main factors threatening the safety of human life. To prevent the occurrences, we must understand the characteristics of electrical hazards. There are four characteristics, as follows.

2.1.Intangibility

Electricity is invisible and inaudible. It presents in all aspects of human life and our work. The electricity is difficult to feel until the electrical fires happen. At the same time, when people get electric shock, the part of current into human body is invisible, even worse the current through the heart, lungs will cause great harm even death.

\subsection{Instantaneity}

The occurrence of electrical hazard is often instantly and caught off guard.

\subsection{Multiple and harmful}

The rate of electrical hazards increased year by year, especially in some places with large power consumption and large flows of people have higher rate, such as schools, institutions and shopping malls. When people contact the current outside of safe range, there will show some bad symptoms in human body, such as muscle spasm, cardiac function impairing, falling and burning, some even die.

\subsection{Time Period}

Electrical hazards often occur in the low voltage power grid is $380 / 220 V$ [3].Electrical hazards are particularly serious in the hot and humid seasons, because in the hot and humid environment human body sweat heavily and the skin become moister, resulting in the decline of human resistance.

\section{The main causes of electrical hazards in the electrical design}

\subsection{Short Circuit}

There are two main causes of electrical short circuit: Firstly, in the case of mechanical damaged, the core of conductor exposed to different potentials conductor. Secondly, some bad conditions such as soaking, lighting, over-heated temperature and mildewing will drop the insulation level of electrical wiring. In the meantime, the external reasons such as overvoltage lightning will breakdown the insulation layer, then the short circuit happens. Thus the short circuit point may be in the electrical junction whose wire connection loose, Along with spark and electric arc, when temperature up to $6000^{\circ} \mathrm{C}$ or above, it will not only burn the insulation material itself but also ignite nearby combustibles.

\subsection{Faulty Contact}

Faulty contact is easily founded in the wire joints or in the junction between wire and other electrical equipment. Especially in the situation that the users use the informal plugs or informal sockets will cause the higher electrical resistance of junction between wire and electric equipment. Then following local overheating with electrical spark and electric arc, all of these are potential ignition sources causing electrical fires.

\subsection{Overloaded Circuit}

The unauthorized accession of electrical equipment will lead to increase of electricity consumption suddenly and occur overloaded circuit. If the engineer doesn't set the overload margin degree in advance the conductor cross section will be too narrow, what's more, long-term overload or rapid increase overload will cause hot melting combustion.

1.4. Grounding Faults

Grounding faults are the common errors electrical engineers may make in the design of the cable 
distribution line of high voltage power system and low voltage power system. During the design of the circuit and the selection of the equipment, electrical engineers often consider the overload protection, over-current protection and the short circuit protection only, rarely have them set up a specific grounding faults protection. As a result, in the case of single-phase-to-earth, the single-phase-to-earth cannot be disconnected instantly which may turn out to be Multiphase-Short-Circuit hazards.

Inadequacy design of low-voltage grounding systems is an important reason for electrical hazards. Low-voltage neutral grounding system is divided into TT grounding system, TN-C grounding system, IT grounding system, TN-C-S grounding system and TN-S grounding system. But the engineers often pay attention to the first two systems only, ignoring other systems design. All of these first two grounding system are still flawed, although they have been designed. Taking the TT grounding method as an example, since the rated current of the TT grounding method is limited, the switch of large-capacity electrical protection equipment will not trip automatically as the single-phase-to-earth short circuit phenomenon emerges.

At this time, the voltage is $220 \mathrm{~V}$, if the neutral resistance is $4 \Omega$ and the load side rounding resistance is $4 \Omega$, then the short-circuit current is:

$$
I_{d}=\frac{U_{\Phi}}{R_{2}+r}=27.5 \mathrm{~A}
$$

In the case of switch failure protection tripping, the power neutral and the device housing will enter the charged state.

Device-to-ground voltage is:

$U_{a}=I_{a} \cdot r=110 \mathrm{~V}$

The result is far beyond $50 \mathrm{~V}$ which means it is unsafe.

Furthermore, the current is:

$I_{r}=\frac{U_{d}}{R_{r}}=\frac{110 \mathrm{~V}}{1000 \mathrm{\Omega}}=110 \mathrm{~mA}$

This current will endanger the safety of the people exposed to it.

Judging from the neutral grounding mode, grounding modes include direct grounding, isolated neutral, resistance grounding, arc suppression coil grounding. When intermittent arc happens to the system using isolated neutral or arc suppression coil grounding, the grounding overvoltage will increase to the original $3 \sim 6$ times, far more than the insulation limit multiple [4]. At this time will produce cable multiphase short circuit, thereby causing electric shock or fire.

1.5. Improper installation of over voltage protection device

In accordance with the relevant provisions high voltage power system and low voltage power system are needed to install over voltage protection devices like arrester, surge protection device, etc. But affected by multiple factors, this equipment is not installed, or installed incorrectly in the electrical design, when lightning occurs insulating material will be struck by lighting and lead to fire. Lightning accident are more likely to happen and more dangerous especially at the high-pressure system and at the weakly insulated parts without the protection of over voltage.

1.6. Inadequate safety measures

Good safety protective measures are important tools to prevent and avoid electrical hazards. But according to the past cable accidents, fire accidents, the safety measures are not enough, especially in fire protection and firefighting when lay cables.

\section{Protective Measures of Electrical Hazards in Electrical Design}

\subsection{Set residual current protection device}

In the electrical design engineers should follow relevant standards strictly that install residual current protection device. What's more, before installing, we should certify quality, confirm parameters and determine grade protection requirements of residual current protection device. Letting the residual current protection device complies with several requirements of low-voltage system phase and neutral grounding system, and adapt to the electrical equipment working environment. 


\subsection{Inspect maximum short circuit current and prevent short circuit}

To prevent electrical hazards effectively, we need to inspect the maximum short circuit current of circuit breakers, current transformers, voltage transformers, high voltage equipment and low voltage equipment and power supply cable.

First, in order to ensure the safety of cable and systems, relevant staff need to provide reliable basis parameters, like the maximum short circuit current parameters of high voltage power system and low voltage power system should be noted in system design drawing and specification in detail. Secondly, check the thermal stability of the maximum short circuit current from the high voltage power system busbar, the low voltage power system busbar, switchgear and the minimum section of infeed circuits cable, to ensure that each value pass check. Finally, relevant staff must provide and note some relevant checking calculation data about the thermal stability of the maximum short circuit current, in order to control the occurrence of electrical hazards from the preliminary design stage and construction design stage.

Short circuit is a key cause of electrical hazards, besides inspecting maximum short circuit current we should delve into the causes of short circuit and take protection to reduce its occurrence. First, select an appropriate short circuit protection device. In the design, the potential transformer, electrical power meter cabinet and power transformers with fuse mode should be chosen. When a short circuit occurs, it can cut off the current timely achieving short circuit protection, over current protection and overload protection. Secondly, to prevent short circuit comprehensively and to reduce the risk of fire, in design of $3 \sim 10 \mathrm{kV}$ high voltage power supply system in our country, in addition to using VCB vacuum cut off at the power receiving point and segment switch, the other infeed circuits can learn from overseas combination switch FC Vacuum Contactors-added Fuse. In the process of test low-voltage transformer short circuit capacity and install the low voltage power supply system with larger capacity, it is possible to use First Commercial Distribution of Electric Power to check the maximum short circuit capacity for the large capacity power distribution circuit, in order to eliminate electrical hazards [5]. To the smaller current distribution circuit, you can use second level power distribution system to check. Eventually, the general over-current protection is not easy to prevent the electric arc short circuit, which is at a heavy big risk of catching fire, but the electric arc grounding faults can be cut off reliably by leakage protector.

In China, leakage protector is mainly used in preventing human body from electric shock and more likely attached to the outlet circuit. In abroad, some power supply companies require that all of electrical wirings should be installed at the power line and use leakage protector for grounding faults to prevent electrical hazards. What' more the total current value that the three single-phase circuits leaked metered by the three-phase leakage protector is far less than its algebraic sum in the power line. Therefore, we can consider setting classification leakage protector started from the power line.

\subsection{Strengthen intelligent monitoring}

At present, there is often not provided single-phase-to-earth protection in the civil building electrical design and replace the single-phase-to-earth protection with the overload protection and residual current alarm system. This approach is quite wrong, at this time, it is recommended to set the grounding protector for the single-phase short circuit in the low-pressure Intelligent Monitoring System, and set a trip or alarm signal to assist grounding point. What's more, the zero sequence current transformer should be set in the design of the power transformer second neutral grounding, the busbar overvoltage grounding protection device and the zero sequence overvoltage grounding protection device should be set in the design of busbar voltage regulator. High voltage system and low voltage system should set multi-functional monitoring system and the control center should set up computers, printers, alarms, etc. What's more, set the communication interface, optical transmission system in the building control center and transformer substation, so as to prevent excessive electricity leakage, large area blackout and electrical fire.

\subsection{Optimize grounding method}

There are four neutral grounding methods and each of them have their own characteristics. For example, the resistance grounding method can reduce over-voltage, ensure the insulation safety of 
the system and has more stable over-current; The single-phase-to-earth method is cheap, reliable and has higher detection sensitivity, but still has a defect that it trips immediately when the grounding faults happen; The arc-suppression grounding method can reduce resonance and lighting grounding faults, and has lower trip rate, but it cannot change the oscillation over voltage peak value and cannot eliminate the arc grounding overvoltage. Therefore, to reduce the incidence of electrical hazards and alleviate the harm through the most appropriate grounding method, when choose the neutral grounding methods we should fully consider the actual situation of grounding and the characteristics of grounding methods.

2.5. Standardize over voltage protection and lightning prevention

Lightning is an important cause of electrical hazards, to prevent fires, electrical design should focus on over voltage protection. For instance, we should set a three-phase arrester in the exits of high voltage circuit breaker and set three single-phase arresters, three interphase arresters and three-interphase resistive and capacitive overcurrent protection after the controllable reactor situ disconnect or of Static Var Compensator(SVC). In the building electrical design, we should also set the lightning rod to prevent direct lightning strike damage. The protection scope of lightning rod is an approximate conical space, and its scope is closely related to the size and height of the lightning rod. When the height of lightning rod is " $\mathrm{H}$ ", its surface protection radius is about "1.5H", by this analogy, when the height of protected object is "h", the surface protection radius given by:

$$
\mathrm{r}=\left\{\begin{array}{cc}
(H-h) \cdot P_{s} & \mathrm{~h} \geq 0.5 \mathrm{H} \\
(1.5 \mathrm{H}-2 h) \cdot P_{s} & \mathrm{~h} \leq 0.5 \mathrm{H}
\end{array}\right.
$$

$P$ is the impact factor of height.

When the height of lightning rod is less than 30 meters, the value of $\mathrm{P}$ is 1 ; when the height of lightning rod is between 30 and 120 meters, the value of $\mathrm{P}$ is $5.5 \sqrt{h}$. When the protected range is relatively large, we can increase the number of lightning rod appropriately to reduce height requirement of the lightning rod [6].

Improve the fire prevention security

Fire safeguards is an important way of fire prevention, and the engineer should do well in the design of fire prevention security, such as determining fire separation distance, setting up oil reservoir facilities and oil sealing facilities, stipulating the setting position of high voltage switchgear, setting fire wall, fire alarms, exhaust fan and so on. Furthermore, we should reinforce the maintenance, updates of the equipment and materials, check the equipment, components and insulation materials of high voltage system and low voltage system. If find some damage, we should carry out treatment timely. What's more, according to the standard, if the equipment and materials over their useful lives, we should fix or replacement them.

\section{Conclusion}

In order to reduce the occurrence of electrical hazards and maintain the public safety, we should fully consider each possible factors that can cause the electrical hazards in the electrical design, and pay attention to the electrical hazards prevention security. Especially, we need to carry on reasonably design aimed at the key factors like short circuit, overload, grounding and overvoltage protection. At the same time, the prevention and preparedness of electrical hazards are a long-term work, which not only require the engineers to make summary in the study but also require the support of community and many departments, through long-term work practices and a full range of joint efforts to reduce the probability of electrical fires occurrence and its harm, guaranteeing the safe operation of power system finally.

\section{Acknowledgement}

This research is supported by Fundamental Research Funds for the Central Universities No.3142015023 \& No.3142013099. 


\section{References}

[1] Chi S. (2013). Harmonic harm and suppression of civil electrical system design. Electrotechnical Application, 6,66-71.(in Chinese)

[2] Zhu Q W. (2012). Basic requirements and design method of mine-used Intrinsic safety power supply. Industry and Mine Automation, 2,22-25.(in Chinese)

[3] Gu B\& Wang T X. (2011). Electric fire protection design of distribution lines laying. Electrotechnical Application. 6,58-61.(in Chinese)

[4] Wang Z Y. (2010). Discussion on the security problem of the national grain electrical design. Electrotechnical Application. 7,74-77.(in Chinese)

[5] Yang C. (2014).Mechanism analysis and preventive measures of fire caused by heat of electric line [J]. Application of Electric, 6, 90-93. (in Chinese)

[6] Chen N, Zhang C Y\& Huang Y. (2013). Design of residual current electrical fire monitoring and detection equipment [J]. Science and Technology of Fire ,12: 1385-1387. (in Chinese) 